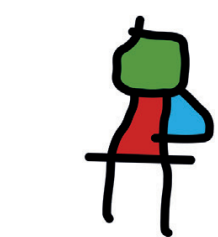

SEICAIP

\section{Allergologia et immunopathologia}

Sociedad Española de Inmunología Clínica, Alergología y Asma Pediátrica

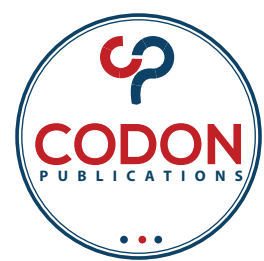

ORIGINAL ARTICLE

OPEN ACCESS (C)(1)(2)

\title{
The CXCR5 T follicular helper cell compartment in children with antibody deficiencies-in search of a prognostic marker of childhood hypogammaglobulinemia
}

\author{
Aleksandra Szczawinska-Poplonyk ${ }^{a *}$, Katarzyna Tapolska-Jozwiaka , Husam Samarab, \\ Maciej Boruczkowski ${ }^{b}$, Barbara Wieckowskac
}

${ }^{a}$ Department of Pediatric Pneumonology, Allergology and Clinical Immunology, Poznan University of Medical Sciences, Poznan, Poland

${ }^{b}$ Department of Immunology, Poznan University of Medical Sciences, Poznan, Poland

'Department of Computer Science, and Statistics, Poznan University of Medical Sciences, Poznan, Poland

Received 20 February 2020; Accepted 25 September 2020

Available online 1 March 2021

\section{KEYWORDS \\ primary \\ immunodeficiency; \\ hypogammaglobulin- \\ emia follicular \\ T helper cells; \\ children}

\begin{abstract}
Background: Novel immunodiagnostic markers are required in order to discriminate between mild hypogammaglobulinemia and severe humoral primary immune deficiencies in children. The efficacy of an antibody response to infections and vaccines is underpinned by $T$ follicular helper (Tfh) cells, activating an immunoglobulin class switch recombination, somatic hypermutations, and affinity maturation.

Objective: To determine the formation of the Tfh cells in antibody deficient children and to define their importance as prognostic markers helpful in defining the severity of hypogammaglobulinemia. Methods: We retrospectively reviewed medical records of 200 children aged from 2 months to 10 years, in whom hypogammaglobulinemia was assessed, from January to December 2019. In all the children studied, a flow cytometric analysis of the Tfh cell compartment was performed. Results: In young infants aged from 2 to 9 months, the mean relative frequency of the Tfh population was lower than in the control population. Concomitantly, the relative values of Tfh cells, corresponding with the 95th percentile, were below the reference values in all age groups.

Conclusions: A deficiency of Tfh cells in young infants mirrors the immaturity of the humoral immune response, whereas in older children Tfh cells are proposed as a prognostic marker facilitating to distinguish between mild hypogammaglobulinemia and the developing common variable immunodeficiency.
\end{abstract}

(C) 2021 Codon Publications. Published by Codon Publications.

*Corresponding author: Aleksandra Szczawinska-Poplonyk, MD, PhD. Department of Pediatric Pneumonology, Allergology, and Clinical Immunology, Poznan University of Medical Sciences, Szpitalna Street 27/33, 60-572 Poznan, Poland. Email address: ola@malwa.com.pl; aszczawinska@ump.edu.pl 


\section{Introduction}

Peripheral blood lymphocyte (PBL) immunophenotyping is an indispensable tool for the precise identification of specific $B$ and $T$ cell developmental defects and for establishing a definitive diagnosis of immunodeficiency. The development of $\mathrm{T}$ lymph cells is a dynamic process reflecting maturational changes within the immune system in children, with the most prominent expansion and shifts within $B$ and $T$ cell compartments in early childhood. In children showing antibody deficiencies, a flow cytometric analysis of peripheral blood B and T lymphocyte subsets may, therefore, provide an accurate insight into their impaired differentiation and maturation. While antibody production defects are the most common category of pediatric primary immunodeficiencies (PIDs), childhood hypogammaglobulinemia is a heterogeneous disorder of complex immunopathogenesis, a diverse clinical course and prognosis, ranging from mild transient hypogammaglobulinemia of infancy to severe agammaglobulinemia with an almost total lack of antibody immune response, and a varied individual immunophenotype with disturbed peripheral blood lymphocyte homeostasis.

An effective $B$ cell immune response and antibody production require the assistance of $\mathrm{T}$ helper cells. Therefore, taking into consideration the immune complexity of childhood hypogammaglobulinemia, in the search for major regulators of antibody synthesis and secretion by $B$ lymph cells, attention has been recently focused on the role of $\mathrm{T}$ follicular helper cells (Tfh). This $\mathrm{T}$ cell subset is characterized by the expression of a B cell follicle homing CXC chemokine receptor 5 (CXCR5) and the concomitant expression of activation and costimulatory molecules, such as CD69, HLA-DR, and the inducible costimulator (ICOS), and is localized within the mantle and light zone germinal centers (GC) of B cell follicles in secondary lymphoid organs. ${ }^{1,2}$ The CXCR5 Tfh cells constitute an activated effector subpopulation of cells and are thought to be entailed in the generation of an efficient antibody immune response. It was shown that Tfh cells play a critical role in assistance to antigen-specific B cells in inducing and maintaining the GC response, which is required for the immunoglobulin class switching and production of IgG and IgA isotypes, somatic hypermutation of the immunoglobulin genes, and the affinity maturation of antigen-specific antibodies, as well as for the generation of long-lived memory B cells, and plasma cells. ${ }^{3}$ CXCR5 T helper cells have also been identified in peripheral blood (PB) and they constitute a subpopulation of cells corresponding with follicular T cells. Alike Tfh cells identified in GC of lymphoid organs, PB Tfh cells potently induce antibody production in $\mathrm{B}$ cells despite their resting memory state and poor ability to migrate in response to chemokines. ${ }^{2,4,5}$ Among three subsets of peripheral blood CXCR5 T helper cells, T helper 1 (Th1), Th2, and Th17 cells; only Th2 and Th17 cell subsets stimulate naive B cells to produce immunoglobulins via interleukin-21 (IL-21). ${ }^{5}$ The help of cognate Tfh to GC homing B cells is therefore indispensable to mount an efficient $B$ cell memory and a high-affinity, long-lived antibody response. Consistent with this, in primary immunodeficiencies characterized by antibody production defects in children, a defective generation of Tfh cells is the background contributing to the impaired humoral response to infections and vaccinations. ${ }^{6}$
It is worth noting that in children, the CXCR5 T follicular cells show a distinct maturational pattern. As demonstrated by Schatorje et al., ${ }^{7}$ who studied the developmental course of $\mathrm{T}$ lymphocyte subsets in children, these CXCR5 memory $T$ helper cells in PB are not identifiable in neonates and dynamically increase in numbers during the first year of life, synchronously to the rise of IgG and IgA isotype production. It is, therefore, an interesting issue whether the assessment of the PB Tfh lymphocyte compartment might help define the pathophysiology of antibody deficiency in children.

This study aimed to understand better the immunopathogenesis of hypogammaglobulinemia in children based on an assessment of the peripheral blood CXCR5 follicular $T$ helper cell subpopulation. We sought to determine if the evaluation of the relationship between an antibody deficiency and the follicular $T$ helper cell compartment would help define and delineate the complex nature of the disease and distinguish the mild transient hypogammaglobulinemia and the defect of developing more severe antibody production.

\section{Materials and methods}

\section{Study group}

We performed a retrospective review of medical records of 200 ( $\mathrm{n}=200$ ) infants and children, 127 boys, and 73 girls, aged between 2 and 131 months (10 years) (mean age 52 months, median age 40 months), who had been referred to the pediatric pneumonology, allergology, and immunology university clinic because of recurrent respiratory tract infections and suspected PID. All the study population was divided into six age groups, following Schatorje et al. ${ }^{7}$ : 2-5 months $(n=16), 6-9$ months $(n=14), 10-15$ months $(n=22)$, 16-24 months $(n=22), 25-60$ months $(n=54)$, and 61-131 months $(\mathrm{n}=72)$. In all the children studied, their serum immunoglobulin levels were below 2 SD of age-matched reference values. A peripheral blood $\mathrm{T}$ follicular helper lymphocyte subset by flow cytometric analysis was performed in all the children studied in whom hypogammaglobulinemia was assessed.

The study was approved by the local institutional Bioethical Committee.

\section{Methods}

\section{Peripheral blood $T$ follicular helper cell immunophenotyping}

Peripheral venous blood samples anticoagulated with ethylenediaminetetracetic acid (EDTA-K2) were stored at a temperature between $4^{\circ} \mathrm{C}$ and $8^{\circ} \mathrm{C}$, and processed within 24 hours. The following monoclonal mouse antihuman antibodies were used for the peripheral blood leucocytes direct fluorescent-labeling: anti-CD45 Fluorescein-isothiocyanate (FITC), anti-CD3 FITC, anti-CD4 FITC, anti-CD185 FITC, antiCD45RO PE, anti-CD3 Peridinin Chlorophyll Protein (PerCP), and anti-CD4 Allophycocyanin (APC; all BD Biosciences, USA). All the blood samples were stained with the correct 
antibody mixture (applied separately), mixed thoroughly, and incubated for 25 minutes in darkness at room temperature (RT). Next, the labeled samples were incubated with lysing solution (FACS Lysing Solution, BD Biosciences, USA) for 10 minutes, washed twice with phosphate-buffered saline (PBS; Roche, Germany), and resuspended in PBS. The labeled cell sample events were collected and characterized using a FACSCalibur flow cytometric cell analyzer (BD Biosciences, USA) and analyzed with FACSDiva software (BD Biosciences, USA). The data acquired was analyzed in two-dimensional scatter plots, with a biparametric (CD45++CD14-) primary lymphocyte gate. The following lymphocyte subpopulations were determined: $T$ lymphocytes (CD3+), $T$ helper lymphocytes $(C D 3+C D 4+)$, and circulating memory $\mathrm{T}$ helper lymphocytes with the CXCR5 (CD185) expression (CD3+CD4+CD45RO+CD185+).

The relative and absolute lymphocyte values as well as the T lymphocyte subpopulation's relative and absolute values were calculated from the patients' leucocyte count and compared with the age-matched pediatric reference values, provided in the study by Schatorje et al. ${ }^{7}$

\section{Statistical analysis}

The results obtained for the study group were compared with data shown in the above mentioned study by Schatorje et al. ${ }^{7}$ (control group) using the single sample t-test. The normality of the distribution was checked using the Kolmogorov-Smirnov test. When the data did not meet the assumptions of normality, it was transformed by applying the logarithm. Tables 1a, 1b, 2a, 2b, 3a, and 3b show the arithmetic mean value and the 5 th and 95th percentiles. All analyses were performed using PQStat v1.6.8 software, assuming the $p$ significance level of 0.05 .

\section{Results}

The general structure of hypogammaglobulinemia in all the study groups is displayed in Figure 1. Overall, defective production of IgG and IgA predominated in the children studied. Where age-matched stratification is applied, different distribution of immunoglobulin deficiency is observed, with panhypogammaglobulinemia being most frequently assessed (in as many as 37\%) in infants aged from 2 to 5 months (Figure 1a). In infants aged from 6 months to 2 years, deficiency of all immunoglobulin isotypes was less frequent and ranged from $2 \%$ to $7 \%$ of patients (Figure $1 \mathrm{~b}$, 1c, and 1d). IgA deficiency, in turn, was predominantly observed in children beyond the age of 2 years (Figure 1e and $1 \mathrm{f})$.

In all the antibody deficient children studied, the T CD3+ mean absolute counts, as well as the mean relative values, were lower than in the age-matched control groups. This tendency to have low $\mathrm{T}$ cell numbers and percentages was statistically significant in all age groups except for the 16-24-months old children; the data are shown in Table 1a and 1b. Likewise, the mean numbers and percentages of $T$ helper CD3+CD4+ cells were lower in the children studied than in the control group. The exceptions were the 16-24-months old children, in whom the decrease of the mean relative value of the $T$ helper $C D 3+C D 4+$ cells was not statistically significant. In children aged 16-24 months and 25-60 months, the mean absolute counts of the $T$ helper $C D 3+C D 4+$ cells were higher than in the control group, albeit without reaching statistical significance; the data are shown in Table $2 \mathrm{a}$ and $2 \mathrm{~b}$.

While the mean absolute numbers of CD4+ $T$ helper cells with the CXCR5 (CD185+) expression were higher in the study group than in the control group and in children aged above 9 months this difference was statistically significant, the mean percentage of CXCR5+ memory follicular $T$ helper cells was diversified depending on the age of the children studied. In infants aged from 2 to 5 months and from 6 to 9 months, the mean relative values of these cells were lower in the study group than in the control group, and in the first group this difference was statistically significant. The absolute deficiency of Tfh cells in infants aged from 2 to 5 months correlated with the highest rate of panhypogammaglobulinemia in this age group.

In children aged from 10 to 131 months, the relative values of Tfh cells were higher than in the age-matched control group and in children aged from 25 to 131 months this difference was statistically significant. In the latter age group, IgA deficiency was most frequently assessed. It is worth noting that, simultaneously, the relative values of Tfh cells corresponding with the 95th percentiles were significantly lower in all age groups of the children studied than in the age-matched control groups. The data regarding the CD4+CD45RO+CD185+ T cells subset are displayed in Table $3 a$ and $3 b$.

\section{Discussion}

In secondary lymphoid organs, the tightly regulated environment of GC, with the surroundings of cellular immune composition and cytokine milieu, Tfh cells assist antigen-activated $B$ cells migrating to the $B$ cell follicles, where they undergo somatic hypermutations and class switch recombination of their immunoglobulin genes. As a result of this GC cellular cooperation, the robust production of high-affinity antibodies of IgG and IgA isotypes occurs. In our study group, all children presented with hypogammaglobulinemia and the predominating type of antibody production defect, assessed in as many as 55\% of the participating children, was a combined IgG and IgA deficiency, followed by an isolated IgA deficiency, which was present in $32 \%$ of them, and a deficiency of all immunoglobulin isotypes occurred in $11 \%$ of them. Therefore, we investigated the production of Tfh cells, looking for a potential common immune denominator for the childhood hypogammaglobulinemia. A deficiency in IgG and IgA production can easily be explained by shifts within the $T$ cell compartment in the first two age groups of infants, in whom the mean relative value of CXCR5+ T cells was lower than in the agematched control group. It is also worth noting that in all the antibody deficient children studied, the 95th percentile of the relative value of Tfh cell was lower than in the control group, potentially implicating a deficiency in the development of T memory cells and the assistance of B cell function and immunoglobulin class-switch recombination. It may also be assumed that the response to vaccines, 


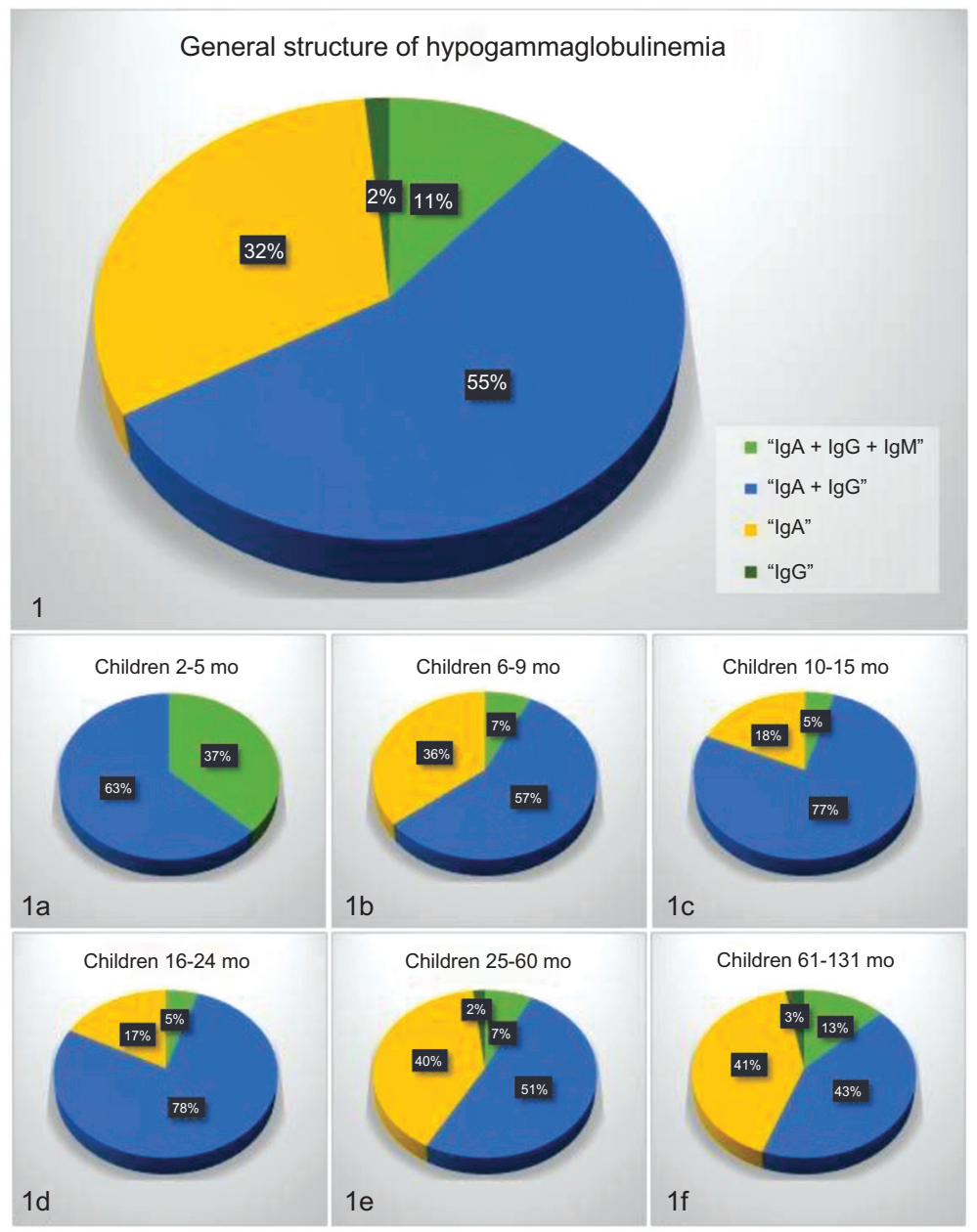

Figure 1 General structure of the antibody deficiency in all the children studied, aged from 2 to 131 months. Figure 1a, 1b, 1c, $1 \mathrm{~d}, 1 \mathrm{e}$, and $1 \mathrm{f}$ display different immunoglobulin deficiencies in different age groups stratified according to the flow cytometric approach.

including protein-conjugated pneumococcal vaccine, which engender a T- dependent antibody response of high avidity and a long-lived immunological memory, might be less effective as a result of the Tfh relative deficiency and the absence of parallel Tfh cell help for B cells. ${ }^{8-10}$ The deficiency and immaturity of the Tfh cell function might also be a deficiency of successful protective humoral response to Haemophilus influenzae capsular antigen with a protein carrier, pertussis, and tetanus toxoid-containing vaccines in infants and young children with hypogammaglobulinemia. ${ }^{11}$

The generation of a potent, high-affinity antibody response indispensable for combating infectious pathogens and for developing an effective response to vaccines, is a multistep process, orchestrated by a plethora of cells and mediators. The cytokine of critical importance for the differentiation of Tfh cells at its early stage of dendritic cell priming is IL-6, inducing Bcl6 expression by newly activated Th cells, required in turn for CXCR5 expression. ${ }^{12,13}$ The most successful conditions yet for Tfh cell differentiation with the induction of Bcl6, CXCR5, and IL-21 expression was shown in the presence of TGF-B and IL-12 or IL-23, ${ }^{14}$ resulting in the generating of Tfh cells with enhanced $B$ cell help activity, and thus an altered cytokine milieu may be a likely contributor to the impaired development of Tfh cells.

A wide spectrum of primary immunodeficiency disorders, resulting from specific gene mutations are also associated with a compromised formation of Tfh cells and their quantitative and qualitative deficiencies. It has been demonstrated that loss-of-function (LOF) mutations in the Signal Transducer and Activator of Transcription 3 (STAT3), CD40 Ligand (CD40LG), Bruton's Tyrosine Kinase (BTK), Nuclear Factor Kappa B Essential Modulator (NEMO), and Interleukin 10 Receptor (IL10R) genes, significantly affect the generation of the Tfh cells, resulting in a reduction of the circulating Tfh cell population in affected patients. ${ }^{15}$ Moreover, altered phenotypes associated with altered functions, with perturbations in cytokine IL10 and IL21 production and skewed differentiation of Tfh cells was shown in STAT3 LOF, STAT1 gain-of-function (GOF), and in the catalytic subunit of phosphatidylinositol 3-kinase (PI3K) GOF mutations, reflecting the impact of these mutations, not only on the quantity of the Tfh compartment but also on its quality. ${ }^{16-19}$ 
Table 1 Mean values and 5th and 95th percentiles (pc) of the relative values (\%) (Table 1a) and absolute counts (\#) (Table $1 \mathrm{~b})$ of the T CD3+ cells. Data are shown for the study group $(n=200)$ and the age-matched control group $(n=71)$ given in the report by Schatorje et al. ${ }^{7}$

\begin{tabular}{|c|c|c|c|c|c|c|c|c|}
\hline & \multicolumn{3}{|c|}{ Study group } & \multicolumn{3}{|c|}{ Control group } & \multirow{2}{*}{$\begin{array}{l}\square \text { mean (study group) } \\
\square \text { mean (control group) } \\
5 \mathrm{pc} \longmapsto\end{array}$} & \multirow{2}{*}{$\begin{array}{c}\text { Comparison } \\
\text { of means } \\
\text { p-value* }\end{array}$} \\
\hline & mean & $5 \mathrm{pc}$ & $95 \mathrm{pc}$ & mean & $5 \mathrm{pc}$ & $95 \mathrm{pc}$ & & \\
\hline $2-5 \mathrm{mo}$ & 51 & 30 & 74 & 69 & 49 & 97 & $\longmapsto$ & 0,0002 \\
\hline 6-9 mo & 55 & 34 & 75 & 68 & 49 & 95 & 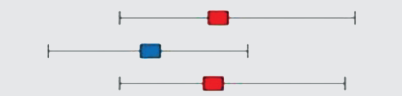 & 0,0078 \\
\hline $10-15 \mathrm{mo}$ & 58 & 39 & 73 & 70 & 56 & 87 & $\longmapsto \square$ & $<0,0001$ \\
\hline $16-24 \mathrm{mo}$ & 58 & 38 & 74 & 60 & 36 & 100 & $\stackrel{\square}{\longmapsto}$ & 0,5417 \\
\hline $25-60 \mathrm{mo}$ & 62 & 45 & 75 & 69 & 52 & 92 & $\stackrel{\square}{\longmapsto}$ & $<0,0001$ \\
\hline \multirow[t]{2}{*}{ 61-131 mo } & 66 & 48 & 81 & 73 & 55 & 97 & $\longmapsto \quad \square$ & $<0,0001$ \\
\hline & & & & & & & 100 & \\
\hline
\end{tabular}

b. $T$ CD3+ cells (\#)

\begin{tabular}{|c|c|c|c|c|c|c|c|c|}
\hline & \multicolumn{3}{|c|}{ Study group } & \multicolumn{3}{|c|}{ Control group } & \multirow{2}{*}{$\begin{array}{l}\square \text { mean (study group) } \\
\square \text { mean (control group) } \\
5 \text { pc }\end{array}$} & \multirow{2}{*}{$\begin{array}{l}\text { Comparison } \\
\text { of means } \\
\text { p-value* }\end{array}$} \\
\hline & mean & $5 \mathrm{pc}$ & $95 \mathrm{pc}$ & mean & $5 \mathrm{pc}$ & $95 \mathrm{pc}$ & & \\
\hline 2-5 mo & 2563 & 1013 & 4303 & 4500 & 2200 & 9200 & $\longmapsto \longmapsto$ & $<0.0001$ \\
\hline 6-9 mo & 3118 & 1173 & 5089 & 4000 & 1400 & 11500 & $\longmapsto \square$ & 0,0423 \\
\hline $10-15 \mathrm{mo}$ & 2738 & 564 & 4455 & 4400 & 2400 & 8300 & $\stackrel{\square}{\longmapsto \square}$ & $<0.0001$ \\
\hline $16-24 \mathrm{mo}$ & 2637 & 612 & 5483 & 2500 & 700 & 8800 & 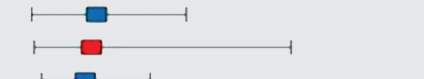 & 0,6632 \\
\hline $25-60 \mathrm{mo}$ & 2291 & 918 & 4348 & 1900 & 850 & 4300 & $\begin{array}{l}1 \square \\
\qquad \square \\
\square\end{array}$ & 0,0090 \\
\hline 61-131 mo & $1418^{* *}$ & $731^{* *}$ & $3135^{* *}$ & 1800 & 770 & 4000 & $\mapsto \bullet \quad$ & $<0.0001^{* *}$ \\
\hline & & & & & & & 12000 & \\
\hline
\end{tabular}

* One-sample t-test, ** after log transformation

Importantly, a deficiency of antibody production may thus result from ineffective Tfh dependent $B$ cell activation in the setting of a disturbed cytokine milieu, a decreased expression of B cell tropic molecules, or a perturbed receptor or intracellular signal transduction. Therefore, in young infants, from 2 to 9 months old, in whom the mean frequencies of $\mathrm{Tfh}$ cells were significantly lower than in healthy controls, estimating the causal relationship between hypogammaglobulinemia and Tfh developmental disturbances requires a more complex approach and the consideration of a transient immaturity of the immune system. ${ }^{20}$ Moreover, common variable immunodeficiency (CVID) is admittedly the most frequent symptomatic primary humoral immunodeficiency, but the diagnosis of CVID, consistently with ESID criteria, can be reliably established after the fourth year of life $\mathrm{e}^{21}$ and therefore, hypogammaglobulinemia in young infants has a limited prognostic value thereof.
A qualitative Tfh deficiency may explain hypogammaglobulinemia in the children studied, in whom the absolute counts and the relative frequencies of Tfh cells were even higher than in the control age-matched groups. Notwithstanding, it is also worth noting that neither the quantitative nor qualitative disturbances of Tfh cells are a hallmark of developing CVID in the antibody deficient children studied. Since CVID is a clinically, immunologically, and genetically heterogeneous group of immunodeficiencies with the common denominator of antibody production defect and a pediatric-onset CVID share a congenial phenotype to adult-onset disease, ${ }^{22}$ it may also be assumed that the GC reaction and Tfh functions in CVID may be variable. It is worth noting that in young children with an early-onset CVID due to a Nuclear Factor Kappa B 2 (NFKB2) gene mutation, a significant reduction in Tfh cells resulting in a disrupted $B$ cell differentiation was demonstrated. ${ }^{23}$ Concomitantly, while in a cohort of adult CVID 
Table 2 Mean values and 5th and 95th percentiles (pc) of the relative values (\%) (Table 2a) and absolute counts (\#) (Table 2b) of the $\mathrm{T}$ helper $\mathrm{CD} 3+\mathrm{CD} 4+$ cells. Data are shown for the study group and the age-matched control group given in the report by Schatorje et al. ${ }^{7}$

a. Th CD3+CD4+ cells (\%)

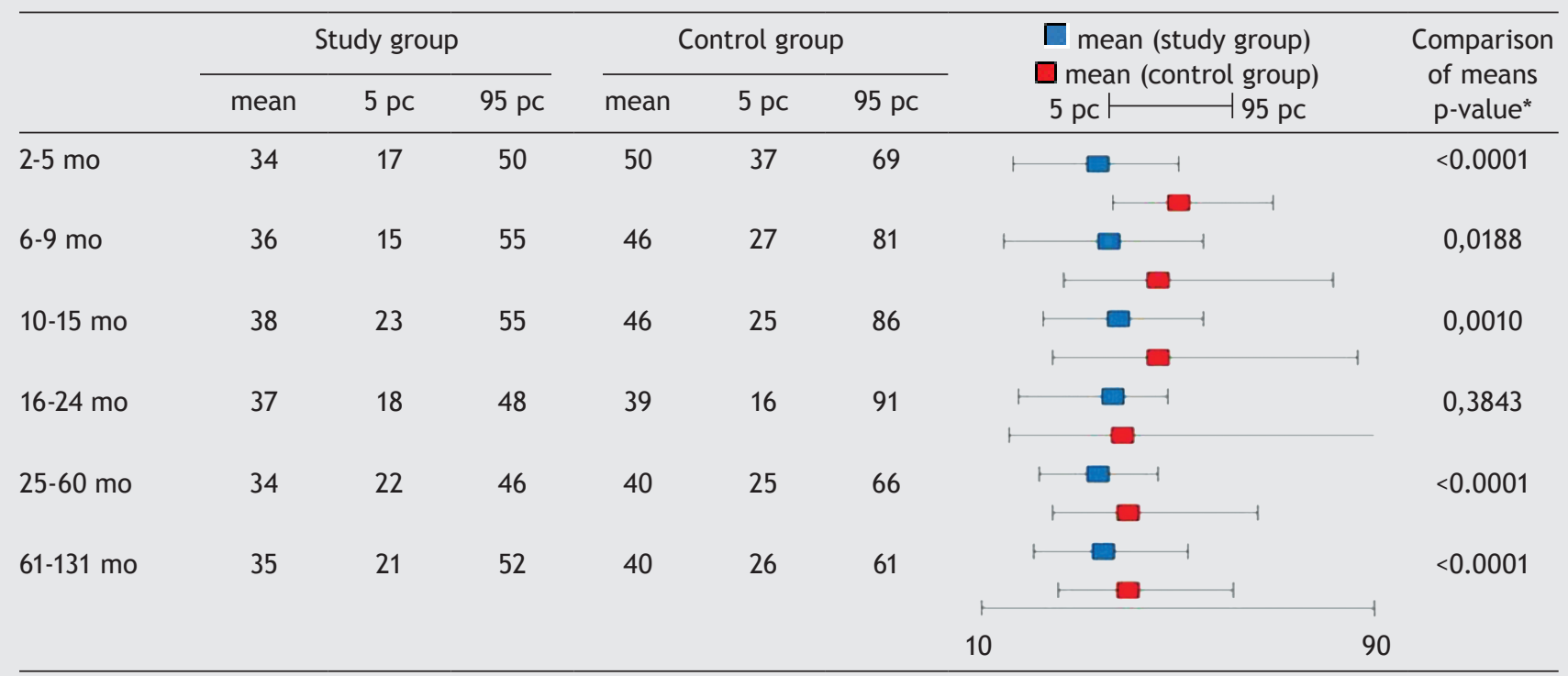

b. Th CD3+CD4+ cells (\#)

\begin{tabular}{|c|c|c|c|c|c|c|c|c|}
\hline & \multicolumn{3}{|c|}{ Study group } & \multicolumn{3}{|c|}{ Control group } & \multirow{2}{*}{$\begin{array}{l}\square \text { mean (study group) } \\
\square \text { mean (control group) } \\
5 \text { pc }\end{array}$} & \multirow{2}{*}{$\begin{array}{l}\text { Comparison } \\
\text { of means } \\
\text { p-value* }\end{array}$} \\
\hline & mean & $5 \mathrm{pc}$ & $95 \mathrm{pc}$ & mean & $5 \mathrm{pc}$ & $95 \mathrm{pc}$ & & \\
\hline 2-5 mo & 1717 & 501 & 3078 & 3300 & 1600 & 6500 & $\longmapsto \square$ & $<0.0001$ \\
\hline 6-9 mo & 2008 & 750 & 3542 & 2700 & 1000 & 7200 & $\longmapsto \square$ & 0,0191 \\
\hline $10-15 \mathrm{mo}$ & 1791 & 349 & 2867 & 3000 & 1300 & 7100 & $\longmapsto \square$ & $<0.0001$ \\
\hline $16-24 \mathrm{mo}$ & 1727 & 398 & 4225 & 1600 & 400 & 7200 & 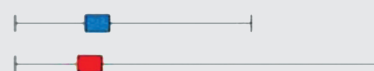 & 0,5818 \\
\hline $25-60 \mathrm{mo}$ & 1258 & 366 & 2263 & 1100 & 500 & 2700 & $\begin{array}{l}1 \square \\
\mapsto \square\end{array}$ & 0,0537 \\
\hline 61-131 mo & $734^{* *}$ & $367^{* *}$ & $1545^{* *}$ & 1000 & 400 & 2500 & $\begin{array}{l}\mapsto \square+1 \\
\mapsto \square\end{array}$ & $<0.0001^{* *}$ \\
\hline & & & & & & & & \\
\hline
\end{tabular}

* One-sample t-test, ** after log transformation

patients due to the Inducible Costimulator (ICOS) gene mutation, the generation of GC was severely disturbed and the numbers of circulating CXCR5+CD45RO+ T helper cells significantly reduced, this being a logical consequence of the ICOS expression on the Tfh cell surface. ${ }^{24,25}$ In another group of CVID patients without a known genetic defect, the Tfh cells were functional and responded to stimulation with an increased expression of costimulatory molecules and intracellular cytokines. ${ }^{26}$ However, intricate interactions between Tfh cells and B cells throughout the GC reaction, followed by CD28 signaling dependent engagement of secondary costimulatory pathways such as ICOS and OX40 (tumor necrosis factor receptor superfamily 4,
TNFRSF4) are also implicated in the development of autoimmunity in CVID. ${ }^{27-30}$ However, in our study group, none of the participating children demonstrated any autoimmune phenomena concomitantly with the antibody deficiency and increased relative frequencies and absolute numbers of the Tfh cells.

\section{Conclusions}

The circulating CXCR5+CD45RO+CD4+ T cells mirror the germinal center $T$ cell-B cell interactions implicating the efficacy of the antigen-specific humoral immune response 
Table 3 Mean values and 5th and 95th percentiles (pc) of the relative values (\%) (Table 3a) and absolute counts (\#) (Table 3b) of the CXCR5+ T follicular helper CD3+CD4+CD45RO+CD185+ cells. Data are shown for the study group and the age-matched control group given in the report by Schatorje et al. ${ }^{7}$

a. CXCR5+ follicular Th CD4+CD45RO+CD185+ cells (\%)

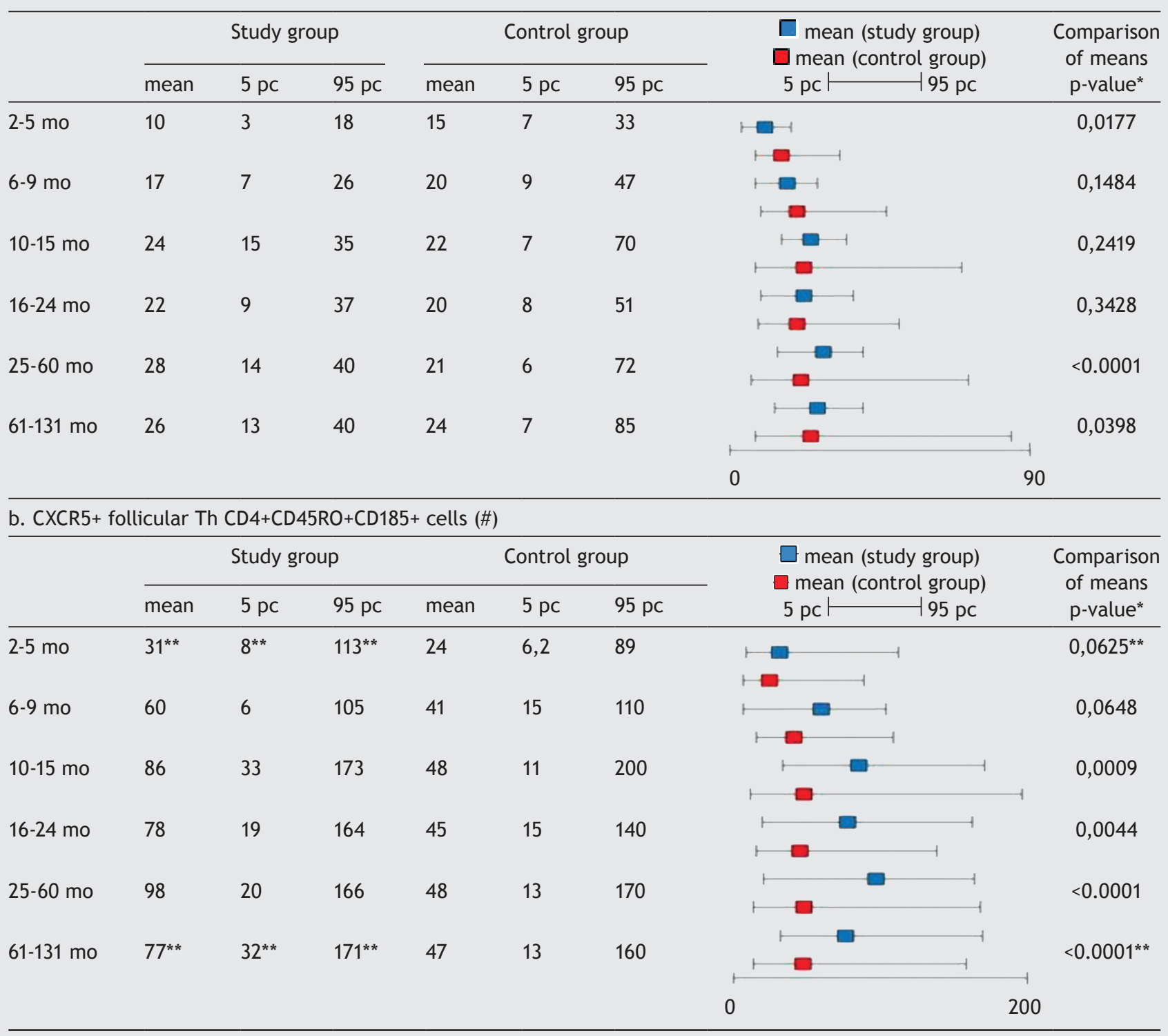

* One-sample t-test, ** after log transformation

due to an immunoglobulin class switch recombination, somatic hypermutation, and antibody affinity maturation. Therefore, the exploration of the Tfh subset in individual cases of children with antibody deficiencies defining their potential role as a trustworthy individual determinant of hypogammaglobulinemia needs to be highlighted.

We propose monitoring the Tfh cell population in antibody deficiencies for diagnostic and prognostic purposes and for distinguishing the transient maturational delay of immunoglobulin production and more severe primary immunodeficiency, thus facilitating a definitive diagnosis of pediatric CVID. Further long-term prospective studies are needed to determine if Tfh cells could indicate CVID by following by the clinical evolution of the patients in correlation with the Tfh cell compartment. The flow cytometric approach will help identify patients with antibody deficiencies persisting beyond the age of 4 years, in whom transient hypogammaglobulinemia of infancy has been ruled out and who do not meet all diagnostic criteria for CVID, and are thus candidates for genetic testing. Identifying a causative gene mutation will facilitate anticipating clinical presentation and establishing a molecular specific diagnosis, excluding these children from umbrella diagnoses, such as CVID or undefined hypogammaglobulinemia. 


\section{Acknowledgement}

Special acknowledgement is due to Professor Anna Breborowicz, from the Department of Pediatric Pneumonology, Allergology, and Clinical Immunology, and to Professor Grzegorz Dworacki, head of the Chair of Immunology and Pathomorphology, Poznan University of Medical Sciences, for their support of the research group.

\section{Competing interest}

All authors declare that they have no competing interest regarding the manuscript.

\section{Statement of financial support}

No financial assistance was received in support of the study.

\section{Author Contributions}

ASzP was responsible for the conception and design of the study, and drafted the manuscript.

KTJ participated in acquisition, analysis and interpretation of data, and helped to draft the manuscript.

HS performed a flow cytometric analysis and participated in the analysis, and interpretation of data.

MB performed flow cytometry and participated in the analysis, and interpretation of data

BW performed the statistical analysis and helped in the interpretation of data

\section{References}

1. Breitfeld D, Ohl L, Kremmer E, Ellwart J, Sallusto F, Lipp M, et al. Follicular B helper $T$ cells express CXC chemokine receptor 5, localize to $B$ cell follicles, and support immunoglobulin production. J Exp Med. 2000;192:1545-5. https://doi. org/10.1084/jem.192.11.1545

2. Schaerli $\mathrm{P}$, Willimann $\mathrm{K}$, Lang $\mathrm{AB}$, Lipp $\mathrm{M}$, Loetscher $\mathrm{P}$, Moser B. CXC chemokine receptor 5 expression defines follicular homing $T$ cells with B cell helper function. J Exp Med. 2000;192:1553-62. https://doi.org/10.1084/jem.192.11.1553

3. Hale JS, Ahmed R. Memory T follicular helper CD4 T cells. Front Immunol. 2015;6:16. https://doi.org/10.3389/fimmu. 2015.00016

4. Ma CS, Phan TG. Here, there and everywhere: $T$ follicular helper cells on the move. Immunology. 2017;152:382-7. https://doi.org/10.1111/imm.12793

5. Morita R, Schmitt N, Bentebibel S, Ranganathan R, Bourder L, Zurawski G, et al. Human blood CXCR5+CD4+ T cells are counterparts of $\mathrm{T}$ follicular cells and contain specific subsets that differentially support antibody secretion. Immunity. 2011;34:108-21. https://doi.org/10.1016/j.immuni.2010.12.012

6. Ma CS, Uzel G, Tangye SG. Human T follicular helper cells in primary immunodeficiencies. Curr Opin Pediatr. 2014;26: 720-6. https://doi.org/10.1097/MOP.0000000000000157

7. Schatorje EJH, Gemen EFA, Driessen GJA, Leuvenink J, van Hout RW, de Vries E. Pediatric reference values for the peripheral T cell compartment. Clin Immunol. 2012;75:43644. https://doi.org/10.1111/j.1365-3083.2012.02671.x
8. Slifka MK, Amanna I. How advances in immunology provide insight into improving vaccine efficacy. Vaccine. 2014;32: 2948-57. https://doi.org/10.1016/j.vaccine.2014.03.078

9. Linterman MA. Can follicular helper $\mathrm{T}$ cells be targeted to improve vaccine efficacy? F1000Research. 2016;5:88. https:// doi.org/10.12688/f1000research.7388.1

10. Jha V, Janoff EN. Complementary role of CD4+ T cells in response to pneumococcal polysaccharide vaccines in humans. Vaccines. 2019;7:18. https://doi.org/10.3390/vaccines7010018

11. Szczawinska-Poplonyk A, Breborowicz A, Samara $H$, Ossowska L, Dworacki G. Impaired antigen-specific immune response to vaccines in children with antibody production defects. Clin Vaccine Immunol. 2015;22:875-82. https://doi. org/10.1128/CVI.00148-15

12. Crotty S. T follicular helper cell differentiation, function, and roles in disease. Immunity 2014;41:529-42. https://doi. org/10.1016/j.immuni.2014.10.004

13. Eto D, Lao C, DiToro D, Barnett B, Escobar TC, Kageyama R, et al. IL-21 and IL-6 are critical for different aspects of B cell immunity and redundantly induce optimal follicular helper CD4 T (Tfh) cell differentiation. PLoS One. 2011;6:e17739. https://doi.org/10.1371/journal.pone.0017739

14. Schmitt N, Liu Y, Bentebibel SE, Mungala I, Bourdery L, Venuprasad $\mathrm{K}$, et al. The cytokine TGF- $\mathrm{B}$ co-opts signaling via STAT3-STAT4 to promote the differentiation of human TFH cells. Nat Immunol. 2014;15:856-65. https://doi.org/10.1038/ni.2947

15. Ma CS, Wong N, Rao G, Avery DT, Torpy J, Hambridge T, et al. Monogenic mutations differentially impact the quantity and quality of $\mathrm{T}$ follicular helper cells in human primary immunodeficiencies. J Allergy Clin Immunol. 2015;136:993-1006. https://doi.org/10.1016/j.jaci.2015.05.036

16. Ma CS. Human T follicular helper cells in primary immunodeficiency: Quality just as important as quantity. J Clin Immunol. 2016;36:40-7. https://doi.org/10.1007/s10875-016-0257-6

17. Ma CS, Wong N, Rao G, Nguyen A, Avery DT, Payne K, et al. Unique and shared signaling pathways cooperate to regulate the differentiation of human CD4+ $T$ cells into distinct effector subsets. J Exp Med. 2016;213:1589-608. https://doi. org $/ 10.1084 /$ jem.20151467

18. Thauland TJ, Pellerin L, Ohgami RS, Bacchetta R, Butte MJ. Case study: Mechanism for increased follicular helper $\mathrm{T}$ cell development in activated PI3K delta syndrome. Front Immunol. 2019;10:753. https://doi.org/10.3389/fimmu.2019.00753

19. Preite S, Huang B, Cannons JL, McGavern DB, Schwartzberg PL. PI3KD orchestrates $T$ follicular cell differentiation in a context dependent manner: Implications for autoimmunity. Front Immunol. 2019;9:3079. https://doi.org/10.3389/fimmu. 2018.03079

20. Gervasi AL, Horton $\mathrm{H}$. Is infant immunity actively suppressed or immature? Virology 2014;2014:1-9. https://doi.org/10.4137/ VRT.S12248

21. Bonilla FA, Barlan I, Chapel H, Costa-Carvalho BT, Cunningham-Rundles $C$, de la Morena MT, et al. International consensus document (ICON): Common variable immunodeficiency disorders. J Allergy Clin Immunol Pract. 2016;4:38-59. https://doi.org/10.1016/j.jaip.2015.07.025

22. Sanchez LA, Maggadottir SM, Pantell MS, Lugar P, Rundles CC, Sullivan KE, et al. Two sides of the same coin: Pediatriconset and adult-onset common variable immune deficiency. J Clin Immunol. 2017;37:592-602. https://doi.org/10.1007/ s10875-017-0415-5

23. Liu Y, Hanson S, Gurugama P, Jones A, Clark B, Ibrahim MA. Novel NFKB2 mutation in early-onset CVID. J Clin Immunol. 2014;34:686-90. https://doi.org/10.1007/s10875-014-0064-x

24. Bosaller L, Burger J, Draeger R, Grimbacher B, Knoth R, Plebani A, et al. ICOS deficiency is associated with a severe reduction of CXCR5+CD4 germinal center Th cells. J Immunol. 2006;177:4927-32. https://doi.org/10.4049/jimmunol.177.7.4927 
25. Jogdand GM, Mohanty S, Devadas S. Regulators of Tfh cell differentiation. Front Immunol. 2016;7:520. https://doi. org/10.3389/fimmu.2016.00520

26. Coraglia A, Galassi N, Fernadez Romero DS, Juri MC, Felippo M, Malbran A, et al. Common variable immunodeficiency and circulating Tfh. J Immunol Res. 2016;2016:4951587. https://doi.org/10.1155/2016/4951587

27. Tangye SG, Ma CS, Brink R, Deenick EK. The good, the bad and the ugly - TFH cells in human health and disease. Nat Rev Immunol. 2013;13:412-26. https://doi.org/10.1038/nri3447

28. Petersone L, Edner NM, Ovcinnikovs V, Heuts F, Ross EM, Ntavli E, et al. T cell/B cell collaboration and autoimmunity:
An intimate relationship. Front Immunol. 2018;9:1941. https:// doi.org/10.3389/fimmu.2018.01941

29. Gensous N, Charrier M, Duluc D, Contin-Bordes C, Truchetet ME, Lazaro E, et al. T follicular helper cells in autoimmune disorders. Front Immunol. 2018;9:1637. https://doi. org/10.3389/fimmu.2018.01637

30. Crotty S. T follicular helper cell biology: A decade of discovery and diseases. Immunity. 2019;50:1132-48. https://doi. org/10.1016/j.immuni.2019.04.011 